\title{
Alternative topical therapy for post-Scabietic Mastocytoid nodules using pimecrolimus cream 1\%
}

\author{
Khalifa E. Sharquie', Mohammed M. Shanshal'
}

\author{
${ }^{1}$ Department of Dermatology, College of Medicine, University of Baghdad, Iraqi and Arab Board for Dermatology \\ and Venereology, Center of Dermatology and Venereology, Medical City, Baghdad, Iraq, ${ }^{2}$ Center of Dermatology and \\ Venereology, Medical City, Baghdad, Iraq
}

Corresponding author: Prof. Khalifa E. Sharquie, E-mail: ksharquie@ymail.com

\begin{abstract}
Background: most recent review of the post-scabietic nodules clinical and histopathological features showed that the mast cells are the predominant cells in $63.63 \%$ either alone or admixed with eosinophils. Pimecrolimus cream $1 \%$ stabilizes the cell membranes and inhibits the release of histamine from mast cells and basophils and reduces the activation of eosinophils. Objective: to evaluate an alternative topical treatment of the post-scabietic nodules according to the histopathological findings. Patients and methods: Thirty-four patients with post-scabietic nodules were treated with pimecrolimus cream $1 \%$ applied to the lesions twice daily for one month. Results: The response after 4 weeks of continuous therapy showed that: A- Seventeen patients (50\%) showed a complete response (complete disappearance of itching and the nodules at the end of the treatment period); B-Nine patients (26.47\%) showed a partial response (partial reduction in the size and number of the nodules with reduction of itching); C- Eight patients (23.52\%) showed no response to therapy (no changes in the size and number of the nodules and severity of itching) Conclusion: Pimecrolimus cream $1 \%$ is an alternative regimen of therapy for the post-scabietic nodules acting through its pharmacological action in the suppression of the inflammatory mediators in the post-scabietic nodules.
\end{abstract}

Key words: Scabies; Post-scabietic nodules; Histopathology; Pimecrolimus

\section{INTRODUCTION}

Post scabietic nodules are one of the commonest manifestations that are seen after the cure and recovery of scabies. A recent review by Sharquie et al showed that post scabietic nodules are non-excoriated, pigmented dusky red in color and had a tendency to occur in specific predilection areas like the scrotum and penile shaft. Darier sign similar to that observed in mastocytosis was reported in $8.82 \%$ and hence the term "post scabietic mastocytoid nodules" was recently applied [1].

The histopathology of post scabietic nodules is a dynamic reaction as the previous studies showed that the main cells in the inflammatory infiltrate are eosinophils and lymphocytes and hence the terms pseudolymphoma and eosinophilioma were used respectively in the past, however; no stain was carried out for the detection of the mast cells [2,3]. While a recent study that used $H \& E$ stain and Giemsa stains revealed that there were three patterns of the inflammatory infiltrate in the post scabietic nodules: eosinophils predominant variant in $36.36 \%$, mast cells predominant variant in $27.27 \%$ and a mixed cellular variant of eosinophils and mast cells in 36.36\% [1].

The already known modalities for the treatment of the post-scabietic nodules including the use of topical and oral corticosteroid, but the drawbacks of these treatments are the plenty side effects [4]. The current study applied pimecrolimus cream $1 \%$ as an alternative modality for the treatment of the post-scabietic nodules relying on its pharmacological actions through stabilizing the cell membranes, inhibiting the release of mediators from the mast cells and basophils and reducing the activation of eosinophils [5].

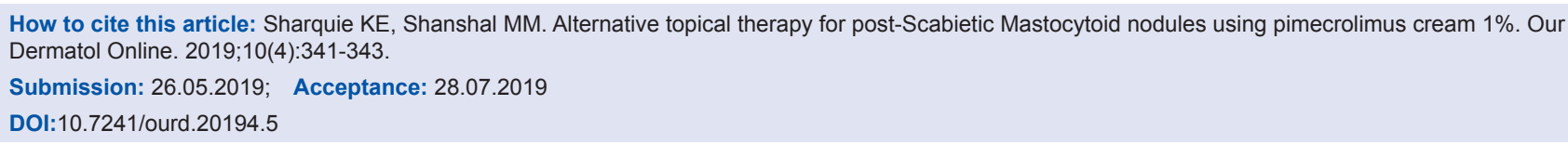




\section{MATERIALS AND METHODS}

This observational therapeutic study was done in the center of Dermatology and Venereology -Baghdad Teaching Hospital, Medical City; Baghdad; Iraq during the period from April 2017- November 2019.

Thirty-four patients with post-scabietic nodules were included in this study, based on the medical history of scabies and clinical examination. Formal consent was taken from all enrolled patients after the nature of the current study was fully explained and ethical approval was performed by the Scientific Council of Dermatology and Venereology-Arab Board for Medical Specialization. The patients were treated with pimecrolimus cream $1 \%$ applied to the nodules twice daily for one month.

Assessment of the patient response to treatment was based on the clinical judgment (change in the itching subjectively by the patients, size and the number of the nodules objectively and by photograph assessment). The response was classified into A- Complete response (complete disappearance of the nodules and itching). B- No response (no change in the size, number of the nodules and the severity of itching).

C- Partial response (any response that is less than the complete response).

\section{Ethics Statement}

Formal consent was taken from all enrolled patients after the nature of the current study was fully explained and ethical approval was performed by the Scientific Council of Dermatology and Venereology-Arab Board for Medical Specialization

\section{RESULTS}

Following the four-week daily application of pimecrolimus cream $1 \%$ to the post scabietic nodules, the response of the patients was as the following:

a- Seventeen patients (50\%) showed a complete response as there was complete disappearance of itching and the nodules at the end of the treatment period (Fig. 1).

b- Nine patients (26.47\%) showed a partial response as there was partial reduction in the size, number of the nodules and itching (Fig. 2).

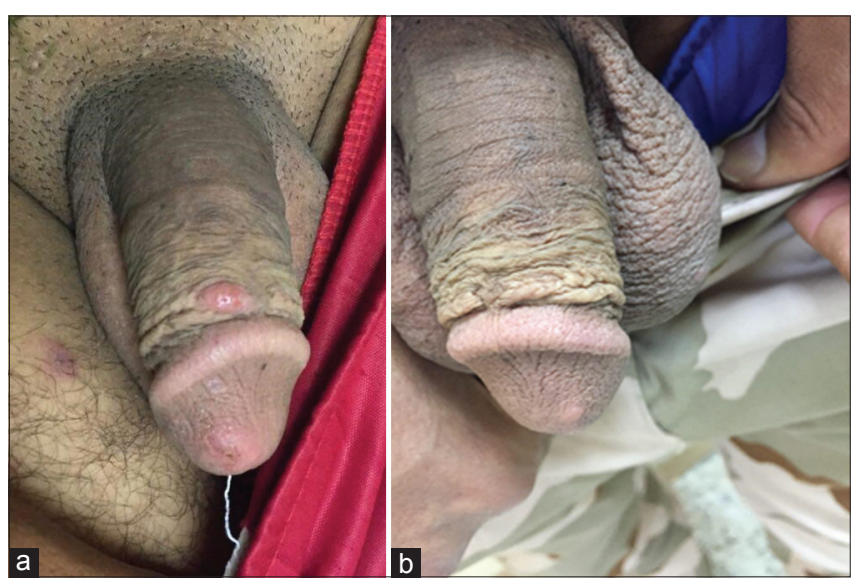

Figure 1: Post-scabietic nodules in thirty years old patient before (a) and after (b) the treatment with pimecrolimus cream, with complete response.

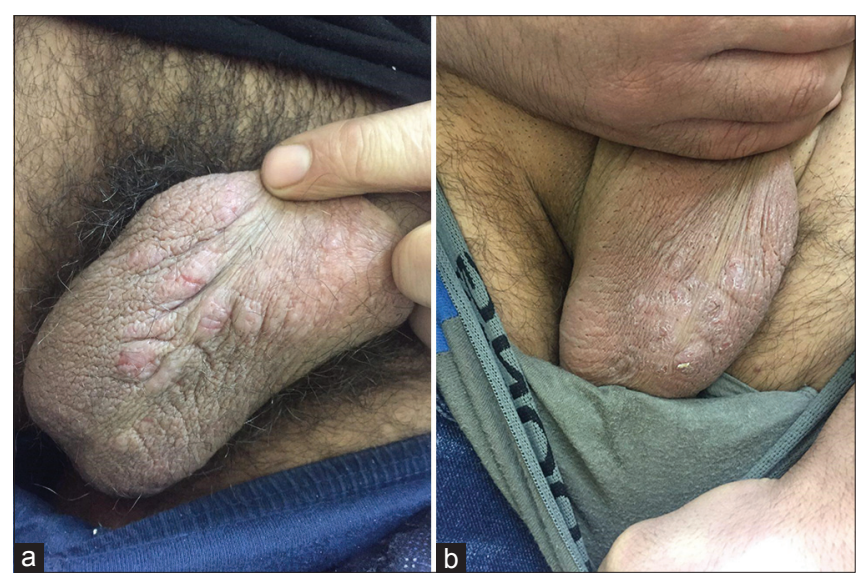

Figure 2: Post-scabietic nodules in twenty-five years old patient before (a) and after (b) the treatment with pimecrolimus cream, with partial response.

c- Eight patients (23.52\%) showed no response as no change in the size and number of the nodules and in the severity of itching.

Side effects were not detected in any of the treated patients. Regarding the relapse rate after cessation of topical pimecrolimus, it could not be determined as the patients did not attend the follow-up visit after they got relief from their disease.

\section{DISCUSSION}

Treatment of post scabietic nodules is often problematic as they respond variably to topical, oral steroid + - antihistamines that are usually followed by a high relapse rate after stopping the therapy [4].

Most recent histopathological evaluation of the post scabietic nodules have shown that the mast cells are 
the predominant cells either alone or admixed with eosinophils in the inflammatory infiltrate of postscabietic nodules. These findings have led us to the use of pimecrolimus cream $1 \%$, a calcineurin inhibitor that has specific effects on the mast cells and eosinophils mainly by stabilizing the cell membrane and preventing their rupture and release of granules [5]. Two previous case reports have evaluated the use of tacrolimus ointment $0.1 \%$, another calcineurin inhibitor, for the treatment of post-scabietic nodules, while only a single case report of successful use of pimecrolimus cream in a single case of steroid-resistant nodular scabies have been reported [6-8].

Hence we planned to use topical pimecrolimus $1 \%$ twice a day for one month as a therapy for these postscabietic nodules and the results were encouraging as $50 \%$ of the patients had complete response with complete disappearance of itching and nodules and $26.47 \%$ had partial response with reduction in itching and nodular number and size while $23.52 \%$ had no response after one month of treatment. Notably, no side effects were reported during the treatment period.

Unfortunately, the limitation of the current study was the difficulty in assessing the relapse rate following the treatment cessation, as most of the treated patients were reluctant to attend the follow-up sessions.

\section{CONCLUSION}

The present work showed that pimecrolimus cream $1 \%$ is an effective alternative treatment for the postscabietic mastocytoid nodules acting through its pharmacological action in the suppression of the inflammatory process in these nodules.

\section{Statement of Human and Animal Rights}

All procedures followed were in accordance with the ethical standards of the responsible committee on human experimentation (institutional and national) and with the Helsinki Declaration of 1975, as revised in 2008 .

\section{Statement of Informed Consent}

Informed consent was obtained from all patients for being included in the study.

\section{REFERENCES}

1. Sharquie KE, Shanshal MM. Post-Scabietic Mastocytoid nodules: a Clinical and Histopathological Evaluation with new Pearls. Am J Dermatol Venereol. 2019;8:37-40.

2. Sharquie KE, Samer AD. Post-scabietic allergic nodules, Clinical and Histopathological study. J Pan Arab Leag Dermatol. 1997;8:29-35.

3. Sharquie KE, Al-Mashhadani SA, Noaimi AA, Katof WM. Clinical and Sequential Histopathological Study of Scabietic and Postscabietic Nodules. Iraqi Acad Scien J. 2013;12supplement):693-9.

4. Zawar V, Pawar M. Liquid nitrogen cryotherapy in the treatment of chronic, unresponsive nodular scabies. J Am Acad Dermatol. 2017;77:e43-4.

5. Gutfreund K, Bienias W, Szewczyk A, Kaszuba A. Topical calcineurin inhibitors in dermatology. Part I: Properties, method and effectiveness of drug use. Adv Dermatol Allergol. 2013;30:165.

6. Reddy DR, Reddy PR. Nodular scabies: a classical case report in an adolescent boy. J Parasitic Dis. 2015;39:581-3.

7. Mittal A, Garg A, Agarwal N, Gupta L, Khare AK. Treatment of nodular scabies with topical tacrolimus. Indian Dermatol Online J. 2013;4:52.

8. de Almeida HL. Treatment of steroid-resistant nodular scabies with topical pimecrolimus. J Am Acad Dermatol. 2005;53:357-8.

Copyright by Khalifa E. Sharquie, et al. This is an open-access article distributed under the terms of the Creative Commons Attribution License, which permits unrestricted use, distribution, and reproduction in any medium, provided the original author and source are credited.

Source of Support: Nil, Conflict of Interest: None declared. 